\title{
Bahraini nursing students' attitudes: from student to nurse-A longitudinal research study
}

\author{
Eman Tawash *, Seamus Cowman \\ School of Nursing and Midwifery, Royal College of Surgeons in Ireland-Bahrain, Muharraq, Kingdom of Bahrain
}

Received: August 11, 2015

Accepted: August 30, 2015

Online Published: September 22, 2015

DOI: $10.5430 /$ jnep.v5n12p79

URL: http://dx.doi.org/10.5430/jnep.v5n12p79

\begin{abstract}
Nursing manpower in the Middle East is highly dependent on expatriates and this presents a challenge in establishing and sustaining indigenous nursing developments. Understanding the perceptions of local nursing students and nurses joining the profession is essential to successful strategies for recruitment and retention of nurses. In contrast to the west, very little is known about this topic in the Middle East. This article aims to identify the perceptions of a Bahraini cohort of nursing students about nursing as a career choice and how these perceptions may change during the course of a programme of nursing education and one year after graduation as a nurse. A longitudinal research design was employed to study the perceptions of the first intake of nursing students enrolled into a new School of Nursing \& Midwifery providing a BSc Nursing Programme; data were collected between 2006 and 2012. A methodological triangulation research approach was used incorporating quantitative and qualitative dimensions. The data collection methods included written reflections, self-administered questionnaires and focus groups. Bahraini nursing students expressed positive perceptions about nursing from their graduate programme years and through the staff nurse year. Observations made about the public image of nursing in Bahrain suggest that nursing is perceived as a low paying, low status job involving excessive hard and unpleasant work. The public perceptions of Bahraini people about nursing may be grounded in strong cultural influences. Any efforts to improve the enrollment and retention of Bahraini nurses should consider enhancing the social values of the nursing profession.
\end{abstract}

Key Words: Perceptions, Nursing, Middle Eastern nursing image, Nursing students, Nurse graduates, Nursing in Bahrain, Culture

\section{INTRODUCTION}

Sustaining a nursing workforce is fundamental to all health care systems and the quality of patient care. The worldwide nursing shortages and aging workforce highlight the importance of improving the recruitment and retention of new nurses within the health care systems. The World Health Organization (WHO) $)^{[1]}$ reported a shortage of 4.3 million healthcare workers globally and estimated that this figure would increase by $20 \%$ over the next two decades. The im- portance of adequate nursing manpower was highlighted in a recent study by Aiken and colleagues ${ }^{[2]}$ which showed that increasing a nurse work load by one patient increased the likelihood of an inpatient dying within 30 days of admission by $7 \%$.

There are 2,800 nurses employed in Bahrain, and 50\% of them are nationals. ${ }^{[3]}$ In some countries of the Middle East, the expatriate nursing workforce may be as high as $80 \% .^{[4]}$ A WHO report ${ }^{[1]}$ declared a world shortage of nurses with a

\footnotetext{
${ }^{*}$ Correspondence: Eman Tawash; Email: eahmed@rcsi-mub.com; Address: School of Nursing and Midwifery, Royal College of Surgeons in Ireland-Bahrain, Muharraq, Kingdom of Bahrain.
} 
need to increase nurses by $70 \%$. A report on the Gulf Cooperation Council (GCC) Healthcare Challenge 2050 ${ }^{[5]}$ states that 230,000 nurses will be required across the GCC countries. At present, in Bahrain there are 4 nurses per 1,000 population compared to the Organization for Economic Cooperation and Development (OECD) average of 8.7. ${ }^{[5]}$ Lovering $^{[6]}$ argued the case for the provision of nursing care that is based on the Muslim worldview. Lovering presented a unique nursing model for Arab Muslim care, which was based on nurses' cultural beliefs and values which supports the case for the indigenous growth of nursing with an increasing Arab nursing workforce.

According to Emeghebo ${ }^{[7]}$ the decision to enter nursing, remain in nursing and to advance in a nursing career may be a result of nurses' perceptions of the profession. The current shortfall of the number of individuals who are pursuing a career in nursing compared with the increasing numbers of those leaving the profession suggests that a positive image of nursing needs to be encouraged by nurse education and the general community in order to attract more individuals to the nursing profession. ${ }^{[8]}$

Studying the perceptions of the nursing students and newly graduated nurses about nursing as a career is very essential as it may give an indication about their plans to remain in the profession. In Bahrain, like in other GCC countries, there is very little research done in this area. This article aims to identify the perceptions of a first cohort of Bahraini nursing students to a newly established school of nursing and midwifery. A particular objective of the study was to explore the perspective of students about nursing as a career choice and how perceptions may change during the course of a programme of nursing education and one year after graduation as a nurse. A longitudinal research design was employed to study the perceptions of the first intake of nursing students enrolled into a new School of Nursing \& Midwifery providing a BSc Nursing Programme; data were collected between 2006 and 2012. The study was conducted in two stages, during the programme years of study and one year after graduation and experiencing work as staff nurses. Some elements related to stage 1 of the study have been previously reported. ${ }^{[8]}$ This paper will focus on comparing the two stages and making conclusions about the changes in the participants' perceptions.

\subsection{International perspectives}

The international literature suggests that the image of nursing as perceived by nurses and the public, affects recruitment of new nurses and retention of experienced nurses, ${ }^{[9]}$ however, Emeghbo ${ }^{[7]}$ claims that no recent studies have been done on how nurses perceive the profession. Researchers have examined perceptions of students at different points in the educational programmes. Studies examining students' perceptions at the beginning of the programme showed that students held idealistic views of the profession, encompassing concepts of caring, nurturing and helping others. ${ }^{[8,10]}$ After experiencing clinical practice, nursing was perceived in terms of technical tasks, documentations and procedural skills. ${ }^{[11]}$

Prospective nursing studies have investigated and defined changes in students' perceptions occurring over time. ${ }^{[12-14]}$ Students' perceptions of nursing evolved from lay to professional images. Nursing studies suggest that these changes occur as a result of students' education. ${ }^{\text {[7] }}$ Safadi and colleagues ${ }^{[12]}$ studied Jordanian nursing students' perceptions over 4 years of the nursing programme, and concluded that students' perceptions progressed from traditional altruistic beliefs to biomedical, technological perceptions. A Changing focus from caring to carrying out procedures was also identified by Pearcey ${ }^{[15]}$ who reported that despite the new trends in nursing that advocate the move away from tasks and routines; holistic care remains a term that is followed by a list of physical tasks with no indications that this term is fully understood by students.

Grainer and Bolan ${ }^{[16]}$ reported a positive image of nursing from first and fourth year students, however, fourth year students had more knowledge of the role of nurses and a realistic perception of the multiple roles and opportunities within nurses. Brodie and colleagues ${ }^{[17]}$ reported that changes in students' perceptions of nursing were related to the amount of education and clinical experiences to which they were exposed. Emeghbo ${ }^{[7]}$ conducted a qualitative study to explore the perceptions of 13 American nurses' about their professional image from just prior to entering the profession and at various stages of their career. The results showed that nursing students begin their nursing education with stereotypical, inaccurate images of nursing and that their nursing school experience seems to neutralize any negative images of nursing. The study also showed that positive nursing role-models reinforced nursing students' beliefs that nursing is a distinguished profession, and notably a survey of registered nurses showed that $36 \%$ of the participants stated they would not recommend nursing as a career option for young people. ${ }^{[18]}$

While rich literature about students' perceptions of nursing is available from the west, very little is known about the perceptions of Arabic nurses.

\subsection{Study aims}

The aims of this study were to identify the perceptions and experiences of a Bahraini cohort of nursing students about 
nursing as a career choice and how these perceptions may change during the course of nursing programme education. A unique and additional objective was to track and identify changes of the cohort one year after graduation as a nurse.

The research questions as stated included: What perceptions do nursing students in Bahrain have about nursing as a career, and do these perceptions change following one year's experience as a staff nurse?

\section{METHOD}

\subsection{Study design}

A longitudinal research design was employed and data were collected in two stages between 2006 and 2012; stage 1 focused on determining the nursing students' perceptions of nursing during their graduate programme, while stage 2 of data collection took place one year following graduation and after the graduates experienced working as hospital staff nurses. Some elements related to stage 1 of the study have been previously reported. ${ }^{[8]}$ This paper will report on the perceptions of nursing during stage 2 (following graduation). The paper will also draw conclusions by comparing both stages.

\subsection{Sample/participants}

The research population was the first intake of nursing students enrolled into a new School of Nursing \& Midwifery providing a first BSc Nursing Programme in September 2006 $(n=38)$. The entire class of 38 nursing students participated in the study. The cohort was all Bahraini nationals and included $5(13 \%)$ males and $33(87 \%)$ females aged between 18-20 years.

\subsection{Data collection}

A methodological triangulation research approach was used incorporating quantitative and qualitative dimensions in order to enrich the findings. ${ }^{[19]}$ The data collection methods included written reflections, self-administered questionnaires and focus groups. Data collection was divided into two stages:

Stage 1: Collection of data from student nurses during their years of participation in the nursing education programme and included three points of data collection:

- Year 1 - Written reflections: participants were asked to reflect on their pre-entry and early entry experiences and understandings of nursing.

- Year 2 - Self-rating questionnaire: participants were asked to complete a questionnaire on perceptions and experiences of nursing. The questionnaire was developed based on the themes extracted from analyzing the written reflections (Year 1).
- Year 3 - Focus group: the participants were assigned randomly into two focus groups of 19 students and interviews were conducted in English and tape-recorded. The interview schedule for the focus groups was developed based on the results of the data collection from written reflections and the questionnaire.

Stage 2: This stage of data collection occurred one year after graduation as a staff nurse. A self-administered questionnaire which was adapted from Anderson ${ }^{[20]}$ was used. The questionnaire was divided into two main sections: Section 1 covered the demographic data related to the graduates. Section 2 included four questions and focused on graduates' perceptions of the nursing profession, their career intentions and their satisfaction with the career decision they made after one year of working as a staff nurse.

The nursing graduates were asked to rate their perceptions of nursing on a 4 point Likert Scale: (1) meant strongly disagree, (2) disagree, (3) agree and (4) strongly agree. The 19 items of this section were grouped into 4 categories; perceptions of nursing education and career potential, nursing professionalism, socioeconomic status of nurses and nursing working conditions.

Following coding, entry of data into SPSS, review and checking was undertaken. The scores related to the negative items on the questionnaire were reversed during computer analysis. Simple descriptive statistical analysis of the quantitative data was undertaken.

\subsection{Validity and reliability}

Content and face validity of the instruments was undertaken through peer review by experienced academics and clinical nursing experts. Pilot tests were undertaken and minor modifications were made to the instruments accordingly. Cronbach's Alpha reported a reliability of 0.79 for stage 1 instrument and 0.72 for stage 2 instrument.

\subsection{Ethical consideration}

Ethics approval for the study was obtained from the University Ethics Committee. Anonymity of the participants was assured throughout the study and no names were written on the questionnaires or the other data collection documents. Students' permission to participate in the study was obtained following detailed explanation of the purpose, methods and expectations of the study and voluntary participation was assured.

\section{RESUltS}

The perceptions of nursing students during the nursing education programme were reported in an earlier study. ${ }^{[8]}$ In this 
paper, the main focus of data reporting will be the perceptions and experiences of the participants one year after graduation (stage 2). This data will be compared with the data collected from participants during the education programme (stage 1). SPSS version 21 was used to analyze quantitative data and Collaizzi's ${ }^{[21]}$ methodology was applied to analyze the qualitative data. Collaizzi's method included extracting significant statements from the qualitative data, formulating meanings from those statements and finally determining clusters of themes.

\subsection{Demographic characteristics}

Thirty two participants graduated, but only 30 progressed to staff nurse and they were invited to participate in stage 2 of the study (graduates). A total of 28 graduate students responded $(93 \%)$. The participants included $93 \%(\mathrm{n}=26)$ females and $7 \%(\mathrm{n}=2)$ males, and the age was $22-24$ years from which $79 \%(n=22)$ were single and $21 \%(n=6)$ were married.

\subsection{One year after nurse graduation}

During the data analysis of the findings, a point which is above the mid-point of the 4 point scale used in the selfadministered questionnaire was considered positive by the researchers, so a mean of 2.5 and above was considered a positive perception and a mean of 2.4 and below was considered a negative perception.

It was identified that "nursing education and career potential" (mean 3.23, SD 0.43) and "nursing professionalism" (mean 3.17 , SD 0.46 ) were the two most highly perceived categories. Participants' perceptions related to the "working conditions" of nurses were the lowest rated category (mean 1.91, SD 0.36).

\subsection{Nursing education and career potential}

The participants viewed nurses as team members with physicians and other health care providers (mean 3.75, SD 0.65). They also viewed nursing as having opportunities for both males and females (mean 3.43, SD 0.63). Noteworthy, the participants rejected the idea of nurses following directions from other health care workers (mean 2.39, SD 0.74) which was the lowest rated item (see Table 1).

Table 1. Nursing education and career potentials $(n=28)$

\begin{tabular}{lll}
\hline & Mean & SD \\
\hline Nurses follow directions from other people & 2.39 & 0.74 \\
Nurses are active in health care research & 2.86 & 0.85 \\
Nurses are well educated & 3.36 & 0.62 \\
Nurses are effective teachers & 3.36 & 0.62 \\
There are opportunities in nursing for men and women & 3.43 & 0.63 \\
Nurses are team members with physicians and others & 3.75 & 0.65 \\
\hline
\end{tabular}

\subsection{Nursing professionalism}

The caring aspect of nursing was highly rated as reflected in the two items; nursing is a caring profession (mean 3.71, SD 0.53) and nurses are important when you are sick (mean 3.36, SD 0.73). Noteworthy the participants rated nurses as lacking control (mean 1.96, SD 0.79) and as autonomous professionals (mean 2.68, SD 0.82) as the two lowest items, although they viewed them as powerful people (mean 3.07, SD 0.90) (see Table 2).

Table 2. Nursing education and career potentials $(n=28)$

\begin{tabular}{lll}
\hline & Mean & SD \\
\hline Nurses lack control of their own practice & 1.96 & 0.79 \\
Nursing is an autonomous profession & 2.68 & 0.82 \\
Nurses are powerful people & 3.07 & 0.90 \\
Nurses are important when you are sick & 3.36 & 0.73 \\
Nursing is a caring profession & 3.71 & 0.53 \\
\hline
\end{tabular}

\subsection{Socioeconomic status of nurses}

The importance of nurses in keeping people well was rated highest by the participants (mean 3.50, SD 0.58). It was also interesting to find that although the participants perceived nursing to offer job security (mean 2.57, SD 0.84), they did not agree that nurses were highly paid (mean 2.39 , SD 1.03) (see Table 3).

Table 3. Socioeconomic status of nursing $(n=28)$

\begin{tabular}{lll}
\hline & Mean & SD \\
\hline Nursing offers high pay & 2.39 & 1.03 \\
Nursing offers job security & 2.57 & 0.84 \\
Nursing is a high prestige occupation & 2.61 & 0.79 \\
$\begin{array}{l}\text { Nurses are important when it comes to } \\
\text { keeping people well }\end{array}$ & 3.50 & 0.58 \\
\hline
\end{tabular}

\subsection{Working conditions for nursing}

Participants rated working conditions as the lowest category. Nurses were perceived to be exposed to dangerous diseases (mean 1.14, SD 0.45) and the working environment to be dangerous (mean 1.75, SD 0.70). The participants also negatively perceived the fact that nurses perform unpleasant tasks when caring for patients (mean 1.75, SD 0.65) (see Table 4).

Table 4. Socioeconomic status of nursing $(n=28)$

\begin{tabular}{lll}
\hline & Mean & SD \\
\hline Nurses are exposed to dangerous diseases & 1.14 & 0.45 \\
Sometimes nurses have to perform & 1.75 & 0.65 \\
unpleasant tasks to care for their patients & & 0.70 \\
Nurses work in dangerous environment & 1.75 & 0.54 \\
\hline Nursing includes much technical work & 3.00 & 0 \\
\hline
\end{tabular}




\subsection{Career plans and intentions}

The participants were asked about their future plans related to the nursing career (see Table 5). The findings illustrated that $75 \%(n=21)$ of the participants expressed their interest to continue with their education. It is important to note that only $25 \%(n=7)$ of the participants were interested in continuing their work as staff nurses.

Table 5. Graduate nurses' career plans and intentions $(\mathrm{n}=$ 28)

\begin{tabular}{lll}
\hline & $\mathbf{n}$ & $\mathbf{\%}$ \\
\hline Enroll in additional education in nursing full time & 14 & 50.0 \\
Work as a staff nurse & 7 & 25.0 \\
Work part time in nursing while continuing nursing & 7 & 25.0 \\
education & & \\
Enroll to study another non-nursing field & 0 & 00.0 \\
\hline
\end{tabular}

\subsection{Satisfaction with the nursing career}

Majority of the participants $(61 \%: \mathrm{n}=17)$ stated they were satisfied with their work as nurses and $21 \%(n=6)$ were enthusiastic about their work in nursing (see Table 6). A relatively high number of participants, $18 \%(\mathrm{n}=5)$ expressed their unhappiness and were planning to change their career.

Table 6. Graduates level of satisfaction with their decision related to a nursing career $(\mathrm{n}=28)$

\begin{tabular}{lll}
\hline & $\mathbf{n}$ & $\mathbf{\%}$ \\
\hline I am enthusiastic about my work & 6 & 21.4 \\
I am satisfied with my work & 17 & 60.7 \\
I am unhappy, plan to change career & 5 & 17.9 \\
\hline
\end{tabular}

\section{Discussion}

A central aim of this study was to explore changes that occurred during the transition from student to staff nurse (stage 1) which has been previously reported. ${ }^{[8]}$ Bearing in mind that this was the first cohort of student nurses at the University and that nursing is a relatively new choice of career in Bahrain, the findings from stage 2 of the study were reassuring in that Bahraini nursing students have continued to express positive perceptions about nursing from their graduate programme years through to the staff nurse years. According to Rheaume and colleagues ${ }^{[22]}$ a positive image of nursing is crucial in attracting applicants to the profession.

Manninen ${ }^{[23]}$ believed that the nursing curriculum can influence students' perceptions of nursing as they progress through the programme. The findings of our study were consistent with other international longitudinal studies. Both Bolan and Grainger ${ }^{[13]}$ and Sand-Jecklin and Schaffer ${ }^{[24]}$ reported that their participants had changed their perceptions of nursing over time. The findings of both studies revealed that as the nursing students progressed in their nursing programme, they showed significantly more positive perceptions towards nursing. In our study it became clear that as the participants mature, their views and perceptions of nursing as a profession maintained a level of consistency, which is congruent with the published literature. ${ }^{[13,25]}$

\subsection{Nursing professionalism}

Nursing as a caring profession and the role of nurses in helping people was clearly articulated during the student and staff nurse transition. It was identified that caring tenets identified during the student stage continued to be a dominant theme; the participants maintained very positive perceptions about the role of nurses in caring for people and being important in keeping people well. ${ }^{[8]}$ Importantly, exposure to work as staff nurses further emphasized this positive perception. Nursing as a caring profession has been presented as a strong theme in the literature. ${ }^{[22,24,26,27]}$

It was interesting to find that as the students matured in their programme, they valued the holistic approach that nurses use in their care of patients which also includes the care of their relatives. The results of this study are in agreement with findings from earlier studies regarding the changes in nursing students' perceptions, that is, students become more professional and see nursing as holistic with the patient as the focus. ${ }^{[25]}$ One year after graduation, the participants perceived nurses to be powerful which was in contrast to participants viewing nursing as having a lack of autonomous and control over their practice. Given that nursing is an evolving profession in Bahrain, it is noteworthy that the findings of the study disagree with Trossman ${ }^{[28]}$ who reported that nurses were stereotypically viewed as women wearing white caps and following physicians' orders without question. Taft and Nanna ${ }^{[29]}$ reported that historically, nurses rarely participated in policy developments that impacted health care delivery and were rarely recognized for their contributions to health care. It has also been reported by $\mathrm{WHO}^{[30]}$ that despite the great developments in both nursing practice and education, nurses were not involved in policy decisions related to the nursing profession. Instead, policies and regulations related to the nursing profession were influenced by politicians, lawyers, doctors and teachers, particularly in relation to nursing education. Among the factors identified as impeding nurses' involvement is the undervaluing of nursing with its associated subordination to medicine and sex discrimination. Nursing includes the characteristics associated with work undertaken by a predominantly female work force: low pay, low status, poor working conditions and few opportunities for promotion. This picture is reflective of the historical evolution of nursing internationally. 
It was also interesting that the study participants started viewing the nursing profession as a high prestigious occupation which offers job security. This reflects the participants" "life orientation" towards nursing, which is described by Vanhanen and Janhonen ${ }^{[31]}$ as nursing viewed as a means of fulfilling life requirements such as balancing family life and career or providing employment and economic security.

\subsection{Status and conditions}

At the beginning of the graduate programme and before the participants were exposed to the clinical experience, they perceived nursing as not enjoyable. As they moved to third year and after having enough experience in the clinical placements they started to realize nursing was challenging and not well accepted socially. ${ }^{[8]}$ The one year experience of working as a staff nurse was vital in reshaping and consolidating the participants' perceptions. In terms of the socioeconomic status of nursing, the participants rating pay as the lowest ranked factor is somewhat juxtaposed to nurses being important in keeping people well. The recognition of nursing as a high prestigious profession was an obvious change compared to the earlier perceptions of students.

Observations made about the public image of nursing in Bahrain suggest nursing is perceived as a low paying, low status job involving much hard and unpleasant work. Socially and culturally in an Arabic society, working shift duty presents problems for females, considering their responsibilities as wives and mothers. ${ }^{[8]}$ In this study, nursing was perceived by the participants as a tough job throughout all stages of the study from student to staff nurse. Whilst students during the first two years of the programme, the participants reported that such perceptions were derived as part of what they have heard from the people they identified as sources for their information about nursing. The most important sources identified included the internet, friends and relative nurses, with the internet being most prominent. ${ }^{[8]}$ As the participants moved to their third year, there was a clear effect of the clinical experience they had. They were more explicit in describing what makes the nursing practice tough and reported issues such as dealing with dirty things, exposure to human bodies, the work load of nurses, as well as the health problems that nurses may suffer from as a result of the type of work they are involved with. This perception was identified further at the staff nurse stage, when the participants indicated that nurses, work in dangerous environments and that they perform unpleasant tasks. These perceptions are realistic considering the nature of nurses' work. Previous themes of nursing as a hard and stressful work have also been expressed in the international literature. ${ }^{[32]}$ According to Sand-Jecklin and Schaffer, ${ }^{[24]}$ the participants in their study believed they had a better understanding on the role of nurses, the complexity of nursing and the high level of work involved in nursing after experiencing a clinical rotation. Seago and colleagues ${ }^{[33]}$ also indicated areas of continued vulnerability for the image of nursing as a profession as most participants considered nursing to be an occupation associated with significant risk of injury which was also reflected earlier in Marriner-Tomey and colleagues. ${ }^{[34]}$

\subsection{Nursing education and career potential}

One of the most important findings related to how the participants perceived nursing education, career potential and the reciprocal relationship between both. At the beginning of the programme, the participants did not perceive nurses to be highly skilled or knowledgeable. During their third year, they were able to recognize the amount of learning and knowledge the nurses are required to gain every day. The actualization of nurses to be well educated was identified clearly one year after graduation. Whilst student nurses (stage 1 of the study), nurses were not perceived to be skilled or knowledgeable, ${ }^{[8]}$ but after working as staff nurses, they recognized the knowledge and high level skills they required to be a professional nurse. These findings agree with Etheridge ${ }^{[35]}$ showing that newly joining nursing students do not appreciate the amount of knowledge required to make important decisions related to patient care. This serves to highlight the importance of a strong knowledge base to nursing education. As McFarlane ${ }^{[36]}$ claimed over 27 years ago "What we have to learn is the intense practicality of theory in practice discipline and its power to transform practice" (p.41).

During stage 2, the participants witnessed the important roles of nurses in research, patient teaching, and as a member of the health team. This positive change might be related to both the nursing programme and the exposure to clinical nursing work. Consistent with international studies, participants perceived nurses to follow directions from other members of the health team and this further supports the perception of nurses as lacking control on their practice.

\subsection{Cultural influences}

The fact that the participants recognized the opportunities available in nursing for both males and females in stage 2 of the study is very crucial, given the international efforts to recruit more males to nursing. In Bahrain, like every other country with a Muslim and Arab culture, people prefer to be cared for by the same gender. There is anecdotal evidence from Bahrain that, culturally, it is not appropriate for females to take care of male patients. ${ }^{[8]}$ The health statistics $^{[3]}$ reported that only $8 \%$ of the nurses in Bahrain are males, although the number of males entering nursing in 
Bahrain is increasing. In the past most cultures in the Middle East, including Bahrain perceived nursing as a natural gift, which required nothing but a caring wife, mother or daughter. Hence, nursing was very much seen as a female job, a fact that discourages many families from encouraging their sons to join a nursing career. Acknowledging this fact, collaborative initiatives should be taken to clear those misconceptions and improve the numbers of male students entering nursing, knowing that attracting more males from Bahrain to join the nursing profession will definitely improve the satisfaction of patients.

Bahrain society is rich in tradition and heritage; however it has experienced profound changes following the discovery of oil. According to Al-Shaikh ${ }^{[37]}$ those changes modified the well-known traditional role of women as to produce children and bring them up. They had an active role in their own homes having no problems serving the family and the supply of "life necessities" was their greater demand. Nowadays, women have gained education and established their position in different jobs and careers. This change and the move from having a family structure of the extended families to more nuclear families increased the demand for women to start depending on domestic maids rather than themselves and their family members to help them raise their children and serve their families. As a consequence of economic developments there is anecdotal evidence to suggest that some young people in Bahrain and other GCC countries may view nurses as maids. The perception of nursing as a "maid's" job might be related to the mass employment of domestic maids as well as using them as nurses in the health care institutions. ${ }^{[38]}$ Again this is another factor to be considered in the development of positive nursing recruitment campaigns.

Any efforts to improve the enrollment and retention of Bahraini nurses should consider enhancing the social values of the nursing profession. According to Cowman, ${ }^{[4]}$ expatriate nurses are a transitory workforce, and this may result in a lack of solidity in creating a nursing workforce, which further presents a challenge in establishing and sustaining health policy and indigenous nursing developments. In addition, indigenous Muslim nurses are believed to provide nursing care that is based on the Muslim worldview. ${ }^{[6]}$ From this perspective, Lovering ${ }^{[6]}$ developed a unique nursing model, the Crescent of Care, which was based on the ways in which nurses' cultural beliefs about health, illness and healing blended with their professional values and care experiences. The indigenous growth of nursing with an increasing Arab nursing workforce is essential to a culturally sensitive care and enhanced communications with Arabic patients. ${ }^{[39]}$

\subsection{Career plans and satisfaction}

Career plans of nursing students are important to health policy developments and also nurse retention in the health services. Spouse ${ }^{[40]}$ reported that students' perceptions of nursing are strengthened or altered depending on the support they receive as they proceed with the programme as well as influencing decisions to leave or continue with the programme. It was very interesting to find that despite having low perceptions in relation to the work conditions, the majority of the participants were satisfied or enthusiastic about being nurses.

The fact that the participants have clear plans to continue their higher education in nursing is promising. Previous studies $^{[24,41]}$ have also found that further study was one of the most frequently cited choices of nursing graduates. On the other hand, the fact that only a minority of the participants, plan to continue their career as staff nurses must be of concern and highlights the importance of structured nursing career clinical pathways. Traditionally in Bahrain, promotion in nursing tends to be away from clinical practice, towards education and management. This finding requires attention from nurse leaders, both in nursing services and education. O'Brien-Pallas and colleagues ${ }^{[42]}$ and an earlier study by Williams and colleagues ${ }^{[32]}$ found that some nursing students use their training in nursing as a foundation course for other careers. Evidence suggests that career advancement programmes help retain expert, highly motivated and effective nurses at the "sharp end" of nursing care delivery, serving as an effective mechanism for developing nurse leaders in clinical practice. ${ }^{[4]}$ From this instance, joint efforts need to be made to ensure that appropriate educational and training opportunities are available for these nurses in order to enhance their satisfaction with their nursing careers in clinical practice.

It is noteworthy that although the working conditions of nursing does not seem to be very satisfactory, none of the participants of this study have intentions to join other non-nursing studies. The finding related to the intention of the "unhappy" participants to change their career is forewarning. It is important that the factors lying behind this unfavorable decision are carefully investigated and efforts to be put in place to promote the retention of nurses. New graduate nurses are a precious human resource and every attempt must be made to ensure enough support for their transition to the professional role of nurses through a positive work environment that promotes their development. ${ }^{[44]}$

\section{Conclusion}

There is very limited discourse on the public image of nursing in the Middle East and the findings of this study provide us with some useful indicators for manpower planning. In 
Bahrain, nursing has traditionally not been an attractive, and at worst has been an unacceptable, career option. The perceptions of Bahraini people of nursing may be grounded in strong cultural influences. ${ }^{[8]} \mathrm{Al} \mathrm{Jarrah}{ }^{[45]}$ claimed that students enter nursing education with inherent amateur beliefs of nursing that develop over the years of their nursing education, empowering them to be professionally socialized into the nursing career. As reflected in the literature, there is a general understanding of the social, educational and political values affecting nursing students, and nursing recruitment and retention in western countries. However, there is very little known about such issues in Bahrain and the other Arabian Gulf countries. There is a need for a strategic approach in managing and directing nursing recruitment drives in high schools coupled with ongoing nursing research on nursing careers. Males continue to be difficult to attract to nursing and a particular emphasis should be placed on this element of recruitment. Noteworthy, culturally, it is more acceptable for male patients to be taken care of by male nurses, and the notion of females providing care and services to male patients is developing, however it remains fragile. Only by positively addressing the culturally sensitive boundaries of nursing in the gulf can we reassure and inform communities and support the indigenous growth of nursing among nationals from the gulf region. ${ }^{[8]}$

Workplace empowerment of nurses needs to be embraced by the health services employers so as to create working conditions that promote work effectiveness, positive work attitudes and better staff satisfaction. The desire to continue higher education supports the requirements for a framework for postgraduate nursing education linked to the scope of nursing practice in Bahrain.

\section{Study limitations}

There are a number of limitations to the study; the sample size was relatively low which does not encourage generalizability of the findings. There is only two schools of nursing in Bahrain and the results are reflective of other student attitudes, given that the nursing students from the two nursing schools share similar demographics and cultural backgrounds.

\section{ACKNOWLEDGEMENTS}

We wish to thank all academic nursing staff from the School of Nursing \& Midwifery in RCSI Bahrain for their support as well as the nursing students of the 2006 cohort who volunteered to participate in this study and deserve sincere thanks and acknowledgements for their participation.

This research received a research grant from RCSI Bahrain (USD 7,950) with special thanks and appreciation.

\section{CONFLicts OF InTEREST Disclosure}

The authors declare that there is no conflict of interest.

\section{REFERENCES}

[1] World Health Organization. The world health report 2006: Health workers [Internet]. 2006. Available from: http://www. who.int/ whr/2006/06_chap1_en.pdf

[2] Aiken L, Sloane D, Bruyneel L, et al. Nurse staffing and education and hospital mortality in nine European countries: A retrospective observational study. The Lancet. 2014; 383(9931): 1824-1830. http://dx.doi.org/10.1016/S0140-6736(13)62631-8

[3] Ministry of Health. Bahrain health statistics. Kingdom of Bahrain: Health Information Directorate [Internet]. 2009. Available from: http://www.moh.gov.bh/PDF/Publications/St atistics/HS2009/hs2009_e.htm

[4] Cowman S. Middle Eastern nursing perspective from Bahrain. Journal of Advanced Nursing. 2014. Available from: http: //online library.wiley.com/doi/10.1111/jan.12488/pdf

[5] Ithmar Capital. Expand, consolidate and support: Meeting the GCC healthcare challenge 2050 [Internet]. 2009. Available from: http://ithmar.com/expand-consolidate-and-s upport-meeting-the-gcc-healthcare-challenge-2050/

[6] Lovering S. The crescent of care: a nursing model to guide the care of Arab Muslim patients. Diversity and Equality in Health and Care 2012; 9: 171-178.

[7] Emeghebo L. The image of nursing as perceived by nurses. Nurse Education Today. 2012; 32: e49-e53. PMid:22079480 http: //dx .doi.org/10.1016/j.nedt.2011.10.015

[8] Tawash E, Cowman S, Anunciacion E. A Triangulation study: Bahraini nursing students' perceptions of nursing as a career. Journal of Nursing Education and Practice. 2012; 2(3): 81-92. http: //dx.doi.org/10.5430/jnep.v2n3p81

[9] Buerhaus P, Donelan K, Norman L, et al. Nursing students' perceptions of a career in nursing and impact of a national campaign designed to attract people into the profession of nursing. Journal of Professional Nursing. 2005; 21(2): 75-83. http://dx.doi.org/1 $0.1016 / j$.profnurs .2005.02.001

[10] Cook T, Gilmer M, Bess C. Beginning students' definitions of nursing: an inductive framework of professional identity. The Journal of Nursing Education. 2003; 42(7): 311-317. PMid:12873061

[11] Pearcey P, Draper P. Exploring clinical nursing experiences: listening to student nurses. Nurse Education Today. 2008; 28(5): 595601. PMid:17950499 http://dx.doi.org/10.1016/j.nedt. 20 07.09 .007

[12] Safadi R, Saleh M, Nassar S, et al. Nursing students' perceptions of nursing: a descriptive study of four cohorts. International Nursing Review. 2011; 58: 420-427. PMid:22092319 http://dx.doi.org /10.1111/j.1466-7657.2011.00897.x

[13] Bolan C, Grainger P. Students in the BN program: do their perceptions change? Nurse Education Today. 2009; 29: 775-779. http://dx.doi.org/10.1016/j.nedt.2009.03.016 
[14] Day A, Field P, Campbell I, et al. Students' evolving beliefs about nursing: from entry to graduation in a four-year baccalaureate programme. Nurse Education Today. 2005; 15: 357-364. http: //dx.doi.org/10.1016/j.nedt.2005.09.003

[15] Pearcey P. Tasks and routines in 21st century nursing: student nurses' perceptions. British Journal of Nursing. 2007; 16(5): 296-300. http://dx.doi.org/10.12968/bjon.2007.16.5.23007

[16] Grainer P, Bolan C. Perceptions of nursing as a career choice of students in the baccalaureate nursing program. Nurse Education Today. 2006; 26: 38-44. PMid:16154237 http://dx.doi .org/10.1016 $/ j$.nedt. 2005.06.004

[17] Brodie D, Andrews G, Andrews J, et al. Perceptions of nursing: Confirmation, change and student experience. International Journal of Nursing Studies. 2004; 41: 721-733. http://dx. doi .org/10.10 $16 / j$.nedt. 2007.07 .006

[18] American Mobile Nurses Healthcare Inc. Survey of registered nurses: Job satisfaction and career plans [Internet]. 2010. Available from: http://assets.fiercemarkets.com/public/ne wsletter/fiercehealthcare/nursesurvey10.pdf

[19] Cowman S. Triangulation. In Watson R, Mckenna H, Cowman S, Keady J (Eds.), Nursing Research: Designs and Methods. USA: Elsevier. 2008: 269-278.

[20] Anderson NE. Factors affecting the selection of a baccalaureate nursing program. USA: Graduate School, Saint Louis University. 1992.

[21] Colaizzi P. Psychological research as the phenomenologist views it. In Valle R, King M (Eds.). Existential Phenomenological Alternatives to Psychology. New York: Oxford University. 1978: 48-71.

[22] Rheaume A, Woodside R, Gautreau G, et al. Why students choose nursing. Canadian Nurse. 2003; 99: 25-29. PMid:12778611

[23] Manninen E. Changes in nursing students' perceptions of nursing as they progress through their education. Journal of Advanced Nursing. 1998; 27(2): 390-398. http://dx.doi.org/10.1046/j.1365-2 648.1998.00521. $\mathrm{x}$

[24] Sand-Jecklin K, Schaffer A. Nursing students' perceptions of their chosen profession. Nursing Education Perspective. 2006; 27(3): 130135.

[25] Granum V. Nursing students' perceptions of nursing as a subject and a function. Journal of Nursing Education. 2004; 43(7): 297-304. PMid:15303582

[26] O'Brien F, Mooney M, Glacken M. Impressions of nursing before exposure to the field. Journal of Clinical Nursing. 2008; 17: 1843-1850. http://dx.doi.org/10.1111/j.1365-2702 .2007.02214.x

[27] Beck C. The experience of choosing nursing as a career. Journal of Nursing Education. 2000; 39: 320-322. PMid:11052656

[28] Trossman S. Caring knows no gender: Break the stereotype and boost the number of men in nursing. American Journal of Nursing. 2003; 103(5): 65-68. http://dx. doi.org/10.1097/00000 446-200305000-00024

[29] Taft S, Nanna K. What are the sources of health policy that influence nursing practice? Policy, Politics \& Nursing Practice. 2008; 9(4): 274-287. http://dx.doi.org/0.1177/1527154408319287

[30] World Health Organization. Nursing and midwifery: A guide to professional regulation. Egypt: EMRO Technical Publications Series 27. 2002.
[31] Vanhanen L, Janhonen S. Factors associated with students' orientations to nursing. Journal of Advanced Nursing. 2000; 31(5): 10541062. http://dx.doi.org/10.1046/j.1365-2648.2000.013 $90 . \mathrm{x}$

[32] Williams B, Wertenberger D, Gushuliak T. Why students choose nursing. Journal of Nursing Education. 1997; 36(7): 346-348. PMid:9309576

[33] Seago J, Spetz J, Alvarado A, et al. The nursing shortage: is it really about image? Journal of Health Care Management. 2006; 51: 96-108. PMid: 16605220

[34] Marriner-Tomey A, Schwier B, Marticke N, et al. Sophomore high school students' perceptions of ideal and nursing career choices. Nursing Forum. 1990; 25(2): 27-30. http://dx. doi .org/10.11 $11 / j .1744-6198.1990 . t b 00846 . x$

[35] Etheridge S. Learning to think like a nurse: stories from new graduates. The Journal of Continuing Education in Nursing. 2007; 38(1): 24-30. http://dx.doi.org/10.3928/00220124-20070101-0 5

[36] McFarlane B. The role of nurse graduates in the health service in the year 2000. Nurse Education Today. 1987; 7: 38-41. http: //dx.doi.org/10.1016/0260-6917(87)90122-5

[37] Al-Shaikh A. An anthropological approach to child asthma in Bahrain: sufferers and their families. 2004 Unpublished PhD Thesis.

[38] Al-Kandari F, Ajao E. Recruitment and retention of nursing students in Kuwait. International Journal of Nursing Studies. 1998; 35: 245251. http://dx.doi.org/10.1016/S0020-7489 (98) 00029-7

[39] Maben J, Al-Thowini K, West E, et al. Uneven development: Comparing the indigenous health care workforce in Saudi Arabia, Bahrain and Oman. International Journal of Nursing Studies. 2010; 47: 392396. http://dx.doi.org/10.1016/j.ijnurstu. 2009.07.00 8

[40] Spouse J. An impossible dream? Images of nursing held by preregistration students and their effect on sustaining motivation to become nurses. Journal of Advanced Nursing. 2000; 32: 730-739. http://dx.doi.org/10.1111/j.1365-2648.2000.01534.x

[41] Zhang M, Petrini M. Factors influencing Chinese undergraduate nursing students' perceptions of the nursing profession. International Nursing Review. 2008; 55: 274-280. http://dx.doi.org/10.11 $11 / j .1466-7657.2008 .00634 . x$

[42] O'Brien-Pallas L, Irvine D, Murray M, et al. Evaluation of a client care delivery model, part 1: Variability in nursing utilization in community home nursing. Nursing Economics. 2001; 19: 267-276.

[43] Adeniran R, Bhattacharya A, Adeniran A. Professional excellence and career advancement in nursing: A conceptual framework for clinical leadership development. Nursing Administration Quarterly. 2012; 36(1): 41-51. Available from: http://www.nursingcen ter. com/lnc/static?pageid=1287302 PMid:22157789 http: //dx.doi.org/10.1097/NAQ.0b013e31823b0fec

[44] Laschinger H, Grau A, Finegan J, et al. New graduate nurses' experiences of bullying and burnout in hospital settings. Journal of Advanced Nursing. 2010; 66(12): 2732-2742. http://dx.doi.o $\mathrm{rg} / 10.1111 / \mathrm{j} .1365-2648.2010 .05420 . \mathrm{x}$

[45] Al Jarrah I. Associate nursing students' perceptions toward nursing profession in Jordan. European Scientific Journal. 2013; 9(6): 147-166. 